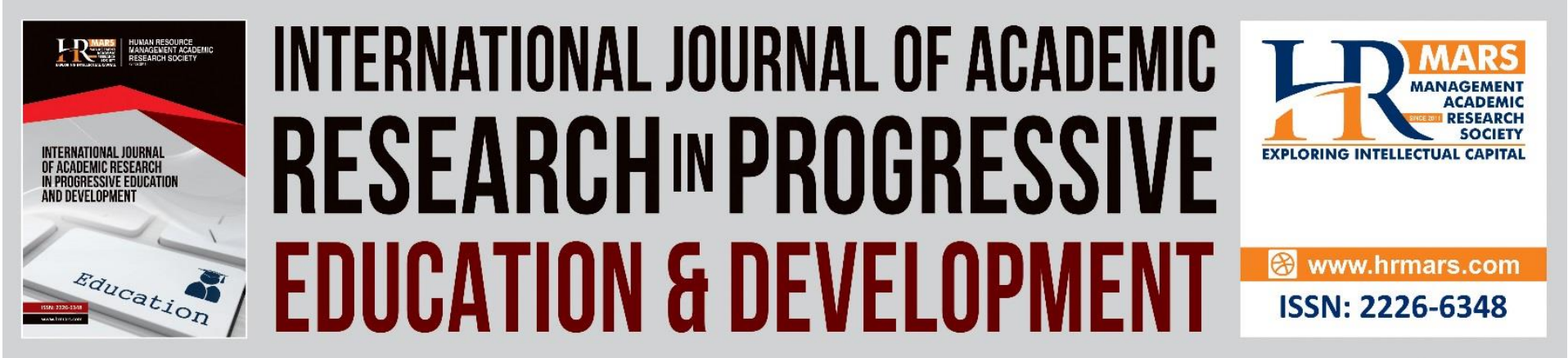

\title{
Utilization of Online Fan-fiction to Improve English Literacy Skills among EFL Undergraduate Students
}

\section{Xiuwen Zhai, Cunyi Liu \& Abu Bakar Razali}

To Link this Article: http://dx.doi.org/10.6007/IJARPED/v10-i4/11678

DOI:10.6007/IJARPED/v10-i4/11678

Received: 18 September 2021, Revised: 20 October 2021, Accepted: 01 November 2021

Published Online: 26 November 2021

In-Text Citation: (Zhai et al., 2021)

To Cite this Article: Zhai, X., Liu, C., \& Razali, A. B. (2021). Utilization of Online Fan-fiction to Improve English Literacy Skills among EFL Undergraduate Students. International Journal of Academic Research in Progressive Education and Development, 10(4), 139-146.

Copyright: (C) 2021 The Author(s)

Published by Human Resource Management Academic Research Society (www.hrmars.com)

This article is published under the Creative Commons Attribution (CC BY 4.0) license. Anyone may reproduce, distribute, translate and create derivative works of this article (for both commercial and non-commercial purposes), subject to full attribution to the original publication and authors. The full terms of this license may be seen

at: http://creativecommons.org/licences/by/4.0/legalcode

Vol. 10(4) 2021, Pg. 139 - 146

Full Terms \& Conditions of access and use can be found at http://hrmars.com/index.php/pages/detail/publication-ethics 


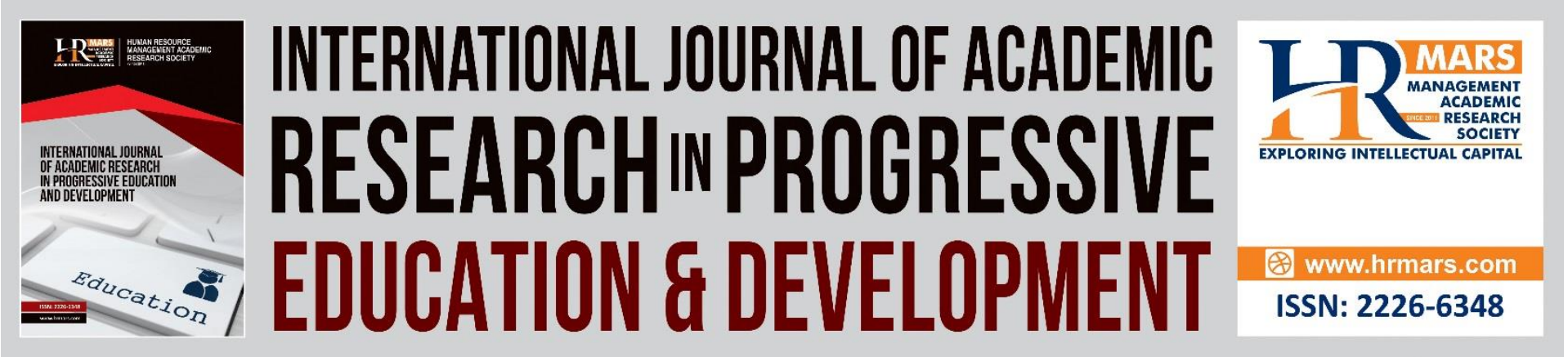

\title{
Utilization of Online Fan-fiction to Improve English Literacy Skills among EFL Undergraduate Students
}

\author{
Xiuwen Zhai, Cunyi Liu \& Abu Bakar Razali \\ Faculty of Educational Studies,Universiti Putra Malaysia
}

\begin{abstract}
The field of language learning and English literacy education has been revolutionized by increasingly developing technology. Innovative and digital literacies have been given birth to English literacy education in the digital arena. Being accessible to the online network website helps expand the production and consumption of international digital citizens. With the access to the internet, these new products and consumption of popular culture have enabled the recent birth of innovative forms of English literacy in English as a foreign language (EFL) settings for tertiary level students as this cohort of students are digital generations who spend lots of time online. So numerous English educators and linguists have turned their attention to the significance of these internet cultures pertinent to English literacy education. The most popular culture being studied by literacy scholars is online fan-fiction in English literacy education. This conceptual paper aims to explore the potential of the utilization of online fanfiction and how it impacts English literacy education in EFL settings and provide the teaching instructions of using online fan-fiction for EFL learners in virtual English literacy classrooms during the pandemic of Covid-19.
\end{abstract}

Keywords: Online Fan-fiction, English as a Foreign Language (EFL), Language Learning, Literacy Practices

\section{Introduction}

In the 21st century, the increase in digital communication has resulted in developing literacy skills that significantly differ from many classroom teachers experienced during adolescence (Bippert, 2017). With the rise of new literacies, more students become literate through reading, writing, communicating, and expressing ideas in the digital world. In such an era when English is used as a language bridge globally, many educators make considerable efforts to explore new methods to teach literacy skills in an English as a Foreign Language (EFL) setting. Furthermore, English literacy education has been challenged by the unexpected disaster of the Covid-19 pandemic. Learning modes in different educational institutions have changed to online methods worldwide (see (Andarwulan et al., 2021; Zhai, \& Razali, 2021).Traditional literacy education has been challenged by digital literacy during the pandemic of Covid-19. Digital literacy should be paid attention to for English literacy teachers and scholars in the current situation (Vorobel et al., 2021). 
One of the techniques used to teach literacy by modern teachers in EFL classrooms is online fanfiction. Fanfiction is a genre of text comprised of original stories created by fans of work and incorporates canon elements of at least one fictional universe (Bahoric \& Swaggerty, 2015). According to Hale (cited in Derecho, 2006: 62), the origin of fanfiction can be traced back to Austen and Sherlock Holmes fan societies in the 1920s. Since the advent of the Internet in 1969, fanfiction has become more popular and widespread. And there is one estimate that online fanfiction comprises one-third of all content about books on the web, which can be a treasury of literature online on a global scale. Thus, if online fanfiction is taken full advantage of in an EFL setting, it is beneficial to improve students' literacy skills and enrich students' understanding of the world.

Scholars in different countries have explored the possibility and practicability of the application of fanfiction or online fanfiction in promoting students' literacy skills (Razali, 2014). Rossetti (2014) found that fanfiction could promote students' skills to comprehend and appreciate reading material. Jones (2015) concluded that fanfiction could make students more engaged in the classroom. He also considered fanfiction an underrated method to improve students' writing skills to prepare them for academic writing. However, there is still much more work to be done in this area. For EFL teachers, they are expected to conduct more practice with online fanfiction in their teaching. Research on the importance of English digital literacy competence for EFL undergraduate students is still needed. So the current study will discuss the potentials and problems of applying online fanfiction for English literacy education for EFL undergraduate students by reviewing previous studies which focused on the utilization of online fanfiction in English literacy education among young EFL learners (Generation-Z).

\section{Previous Research on the Application of Online-fanfiction Aids in Teaching Literacy in Tertiary-level: Potentials}

Traditional literacies have historically focused on the ability to read and write effectively. In the past, students become literate via traditional print modes. Nowadays, it can be argued that students participate in literate behaviors, often through digital means (Bippert, 2017). Students, especially tertiary level students who are more sensitive to the change of new technology, are significant consumers of online information in the 21st century, an era with the boom of new media and massive news (Bahri et al., 2021). At the same time, the advance of technology makes them become lucky learners who can benefit a lot from new literacies. But what might not be a piece of good news for some teachers is that there is a tendency that more tertiary students are unwilling to read and write on papers as mobile devices and the internet are available for them, which poses severe challenges to the traditional methods to teach literacy inside classrooms for the reason that students' attention is drawn outside the school. However, as every coin has two sides, the challenges posed by new technology can also urge teachers to apply new techniques to teach literacy by using new technology. To bridge students' digital media experiences with in-school literacies, teachers can provide support through online fan-fiction.

The application of online fan-fiction can positively affect the improvement of literacy skills, both reading and writing skills, for tertiary level students in an EFL setting (Black, 2006, p. 177). For readers, reading could be regarded as a method to escape reality and to enter a whole new world. Literature is a kind of frequent source of inspiration for the cinematographic industry, from the movies that are loosely based on a book to those that try to be as faithful to the source text as possible. EFL Learners could feel more motivated and 
more engaged in reading if required to compare the movie to the book (Rossetti, 2013). Thus, those online fan-fiction related to the film and television works or other forms of art students like can inspire students to read.

What's more, asking students to read fan-fiction can allow them to read facets of the same works through different fan-fiction authors' words and perspectives, allowing for a much deeper exploration of the text, which can also contribute to student's skills of critical reading. Then, it needs to be mentioned that online fan-fiction also contributes positively to developing two basic reading strategies: scanning as well as skimming. When the number of stories is overwhelming, fans either trust the synopsis or scroll via the stories and assess which one seems to be the most interesting. Suppose they wish to know how an author could handle a particular setting anticipated in the synopsis or pertinent to the source material. In that case, they skim through the fan fiction, looking for a specific moment if dealing with a fill-in fan fiction. Of course, since reading fanfiction is written for interests, extensive reading is engaged more often than not. Moreover, for those tertiary-level students occupied with other things like part-time jobs, reading online fanfiction will be easy to access leisure while their reading skills can be trained.

Online fanfiction can also produce positive effects on tertiary students' writing skills. In the writing class of the EFL setting, one of the main challenges teachers can encounter when creative teaching writing is teaching students to get past the blank page. Especially when students are required to write creative narratives, they are asked to complete a much more complex task. Writing a completely new story involves creating characters and a world for them to live in. Fortunately, they can get much inspiration after receiving enough input from online fan-fiction, which can work as the best examples for plotting a story.

Furthermore, teachers can also guide students to create their fan-fiction based on their interests in class and online, demanding that they take different perspectives on familiar situations and stories, making meaningful connections with the texts they read in class. Another advantage lies in the high degree of share-ability and interactivity of using online fanfiction. When students write fan-fiction online, the teacher is not the only reader or audience. Other students can also have access to decoding the online content written by their classmates and provide feedback for further improvement. The process students read and decode online fan-fiction benefits their creative reading skills, while the process students write feedback hones their writing skills to select and organize their words carefully. After receiving feedback from readers, the authors try to polish their works by using more rhetorical tactics or make a more detailed description, which further builds students' writing ability.

\section{Underpinning Theory: Scaffold Theory in English Literacy Teaching}

The technique is based on the theory of 'scaffolding,' which has been widely and widely used in the literacy class, being regarded as the transfer of task role, responsibility, and authority from the teacher to the student. According to this theory, students' initiative and involvement are prioritized with implementing the online-fanfiction technique in literacy teaching in an EFL setting. Teachers play the roles of collaborators, which transforms the class into a studentcentered class. In the digital era, online-fanfiction literacy classes can enhance students' motivations and entertainment. Indeed, the concept 'scaffolding' was first used by Wood, Bruner and Ross (1976) to examine parent-child talk in the early years. "Scaffolding"-in its more usual sense is a temporary structure that is often put up in constructing a building. As each bit of the new building is finished, the scaffold is taken down. So in the implementation of online fanfiction in literacy teaching to tertiary level students in EFL, students are the owner 
of the class, and teachers play the roles of collaborators. Teachers release the class power to their students. Students are centered in this class by selecting the topic they like, the presentation form they are familiar with.

\section{Innovative Pedagogical Procedures}

The whole process involves two abilities: reading and writing. When students get the meaning from the original fiction, it needs reading ability. Meanwhile, students need writing ability to write fanfictions. So literacy abilities can be taught in this teaching technique.

In the first procedure, teachers can present some online-fanfiction websites to the students, divided into four groups, by the types of fanfiction (books, movies, games, TV shows). Each group is provided a corresponding example of fanfiction and its reviews with four assignments:1)summarize the piece 2)rate the piece after a review of what to look for 3)make suggestions for improvement 4)identify a helpful review (Kell, 2009). Secondly, teachers should give examples to students on how to read like a fan and get these cohorts of EFL learners thinking about writing simultaneously, as well as brainstorming how to add something to fill the gap by performing the teaching strategy of teaching a class novel or facilitating literature circles. In this procedure, teachers can help enhance students' six reading abilities: decoding, fluency, vocabulary, sentence structure and cohesion, reasoning and background knowledge, as well as a work memory and attention, as well as teaching students to master the scanning and skimming skills to improve their reading speed. Meanwhile, reading is not only the recognition of words at a glance or decoding the meaning of letters or words strewn together but also a conscious and unconscious thinking process whereby the reader applies various strategies to infer the author's original intended meaning. The readers' prior knowledge and information bank on the given topic; in other words, the reader's schemata are used to reconstruct the importance of the text. Researchers in text comprehension state that the textual data in the form of shapes and sounds of the letters, the meanings of words or letters, and grammatical information is processed by the reader, which is then processed in light of his existing schemata. So in this process, teachers should help the students master the capability of analyzing the content relatively correctly. For second-language learners hence, they need to learn to think in English to read this language effectively and be taught some reading skills like previewing and predicting the outcome of a text, questioning the author's intentions, or identifying relationships between ideas. While these skills should be taught one by one, teachers can teach their students one skill ideally at a time. The learners can be asked to work upon one skill with a partner and discuss their thinking to improve a good command of the skills. These skills are very vital for students to master the excellent knowledge of English reading ability. Teachers should encourage students to do critical reading and trans-literacy by asking students to re-imagine the story in a different media, which can stimulate students' motivations in literacy class.

In the second procedure, teachers will teach some writing skills to students to improve their writing ability, which consists of having good vocabulary, correct grammar and spelling along with perfect punctuation, as well as coherence and cohesion skills which refer to the structure and flow of your essay and its paragraphs. Design means how your writing and sections are organized, and flow means that your ideas are connected logically and skillfully. To achieve these goals, English teachers could begin through the teaching procedure of modeling the activity, doing it with the class, and then asking students to write independently. The procedures are shown as follows:

(1) Choose a passage from the source text which makes descriptions of a setting in the story. 
(2) Read the article carefully and annotate the distinguished features as well as techniques the narrator employs to establish an accurate description.

(3) Write a detailed description of the innovative setting for a fan-fiction story.

(4) Make descriptions of the situation in a similar scope to the initial, or zoom in or out to describe part of the situation not mentioned in the source.

Teachers can let the four groups (books, movies, games, TV shows) write fan-fiction assignments, which makes writing a great way to scaffold the process as they don't need to worry about creating original characters, to improve their writing skills by giving full feedback to their homework to provide their a motivation to write. What's more, students can select a website (Fan-fiction, Quotev, Kindle Worlds, Wattpad, Archive of our own, AsianFanfics, deviantART) by themselves to submit their own fanfiction one chapter a week. Teachers should give effective comments according to their content, grammar, cohesion, and coherence. When stories have been posted online, students are required to keep an eye on the feedback from their readers. The more these cohorts of EFL learners interact with their readers, the more ideas they will get from others. Sometimes students can edit more from readers' comments.

\section{Strengths \&Weaknesses}

Literacy skills are very significant for any tertiary-level student to acquire access to knowledge in their academic life. Many of them face difficulties comprehending their educational reading materials and reading at the surface level; mainly, most of them are not motivated to learn literacy. So reforms are needed in the traditional teaching literacy method. Adopting online fan-fiction aids can make the literacy class more dynamic and entertaining. Meanwhile, it can stimulate students' motivations. However, drawbacks also exist in using online fan-fiction aids in literacy teaching. Firstly the content should be selected thoughtfully before using it in class. Meanwhile, Comments on the internet may influence students' motivations in writing because there is no specific, powerful law to protect people's rights on the internet. The existence of internet comments violence may be harmful to students' interests and perseverance in writing. Thus, for the students in rural areas without stable internet, they have difficulty embracing the benefits brought by online fan-fiction. Some teachers without a good command of computer technology cannot fully use the resources online.

In conclusion, regardless of its disadvantages, online fan-fiction can still be regarded as a practical technique in literacy class to tertiary level students in EFL, which can help improve students' literacy capabilities. It is easier for students to write because it is already halfway done for the author, who needs to make the right connections and write fan-fiction. Teachers could adopt this tool when teaching literacy to improve student's literacy skills. In the 21st century class, digital tools could be adopted in the course to make the class dynamic and entertaining.

\section{Motivations \& Contributions}

The motivation for researchers to do this research is that the authors want to help make contributions to the teaching approach on literacy education during the pandemic of Covid19 or post-pandemic Covid-19 period. Due to the outbreak of Covid-19, most higher education institutions shift the teaching and learning mode from face-to-face physical interaction mode to online learning mode. Thus, English literacy education is negatively influenced by using the online-learning method. Students are out of control by teachers compared with the previously physical-learning approach. Interactions with teachers and 
colleagues are decreased. Hence, the quality of literacy teaching and learning education is reduced.

Furthermore, it has been reported by previous studies that students and teachers face increasing mental problems, low-level learning motivation,loneliness-related learning problems at this particular period (Tejedor et al., 2020; Zhai \& Razali 2021). All these existing problems stimulate the authors' motivation to write this article. Online fan-fiction could help enhance EFL/ESL learners' motivation in literacy practice, and it could also help increase the chances of interacting with others in the international community. So these advantages could help improve EFL/ESL students' writing performance and help alleviate their mental problems. It has been argued by Tejedor et al. (2020) that online learning and remote learning cause loneliness to young learners, which negatively influences their mental health. So the application of online fan-fiction in literacy education could contribute to providing an alternative for literacy teachers in the current situation of Covid-19. Furthermore, the authors hope literacy educators, scholars, and teachers could explore a more effective and exciting teaching and learning approach in literacy education to help make learning literacy for young learners more attractive and help make this world a better place.

\section{References}

Andarwulan, T., Al Fajri, T. A., \& Damayanti, G. (2021). Elementary Teachers' Readiness toward the Online Learning Policy in the New Normal Era during Covid-19. International Journal of Instruction, 14(3), 771-786. https://dx.doi.org/10.29333/iji.2021.14345a

Bahoric, K., \& Swaggerty, E. (2015). Fanfiction: Exploring In- and Out-of-School Literacy Practices. Coloraddo Reading Journal, 25-31.

https://www.academia.edu/14343625/Fanfiction_Exploring_in_and_out_of_school_lit eracy_practices

Bahri, A., Idris, I. S., Muis, H., Arifuddin, M., \& Fikri, M. J. N. (2021). Blended Learning Integrated with Innovative Learning Strategy to Improve Self-Regulated Learning. International Journal of Instruction, 14(1), 779-794. https://dx.doi.org/10.29333/iji.2021.14147a

Bippert. K. (2017). Fan Fiction to Support Struggling Writers. Texas Association for Literacy Education Yearbook: Literacy Alive and Well! Supporting Effective Literacy Instruction for All Learners, 12(4), 17-27 https://www.academia.edu/34808025/Fan_Fiction_to_Support_Struggling_Writers

Black, R. W. (2005). Access and Affiliation: The Literacy and Composition Practices of EnglishLanguage Learners in an Online Fanfiction Community. Journal of Adolescent \& Adult Literacy, 49(2), 118-128. https://dx.doi.org/10.1598/jaal.49.2.4

Black, R. W. (2006). Language, Culture, and Identity in Online Fanfiction. Learning and Digital Media, 3(2), 170-184. https://dx.doi.org/10.2304/elea.2006.3.2.170

Black, R. W. (2007). Fanfiction Writing and the Construction of Space. E-Learning and Digital Media, 4(4), 384-397. https://dx.doi.org/10.2304/elea.2007.4.4.384

Derecho, A. (2006): Archontic Literature: A Definition, a History, and Several Theories of Fan Fiction. In Karen Hellekson und Kristina Busse. (Hrsg.), Fan fiction and fan communities in the age of the Internet: new essays (pp. 61-78). North Carolina: McFarland Press. https://link.springer.com/chapter/10.1007/978-3-531-93261-3_20

Guasch, T., Espasa, A., Alvarez, I. M., \& Kirschner, P. A. (2013). Effects of feedback on collaborative writing in an online learning environment. Distance Education, 34, 324338. 


\section{DEVELOPMENT}

Vol. 10, No. 4, 2021, E-ISSN: 2226-6348 @ 2021 HRMARS

http://dx.doi.org/10.1080/01587919. 2013.835772

Jewitt, C. (2008). Multimodality and Literacy in School Classrooms. Review of Research in Education, 32(1), 241-267. https://dx.doi.org/10.3102/0091732x07310586

Jones, G. (2015). Fanfiction Rules Writing Research. Stylus Knights Writer Showcase Special Issue, 1-6.

Razali, A. B. (2014). Online popular culture in language learning: Reading and writing online fanfiction. In Proceedings of the 22nd International Conference on Computers in Education (pp. 762-767), Japan: Asia-Pacific Society for Computers in Education.

https://writingandrhetoric.cah.ucf.edu/wpcontent/uploads/sites/17/2019/10/KWS3_Jones.pdf

Rossetti, E. (2014). Reading and writing fan fiction in English as a foreign language: a survey study, PHD dissertation, Ca' Foscari University of Venice. http://dspace.unive.it/bitstream/handle/10579/4382/838977-1167892.pdf?sequence $=2$

Tejedor, S., Cervi, L., Pérez-Escoda, A., \& Jumbo, F. T. (2020). Digital Literacy and Higher Education during COVID-19 Lockdown: Spain, Italy, and Ecuador. Publications, 8(4), 48. https://doi.org/10.3390/publications8040048

Vorobel, O., Voorhees, T. T., \& Gokcora, D. (2021). Language learners' digital literacies: Focus on students' information literacy and reading practices online. Journal of Computer Assisted Learning, 37(4), 1127-1140. https://dx.doi.org/10.1111/jcal.12550

Zhai, X. W., Razali, A. B. (2021). An Overview of the Utilization of TikTok to Improve Oral English Communication Competence among EFL Undergraduate Students. Universal Journal of Educational Research, 9(7), 1439 - 1451.

https://dx.doi.org/10.13189/ujer.2021.090710 